\title{
Analyzing the Listening Activities That Match the Listening Specific Outcomes in the Jordanian Guidelines for the Pupil's Book of Action Pack 5
}

\author{
Issam Mostafa Taamneh (Corresponding author) \\ Languages and Translation Department \\ Tabuk University, KSA \\ Tel: 966-580-102-085 E-mail: dr.issamtaamneh@gmail.com
}

Received: February 13, 2018 Accepted: March 8, 2018 Published: March 12, 2018

doi:10.5296/ire.v6i1.12657ＵRL: http://dx.doi.org/10.5296/ire.v6i1.12657

\begin{abstract}
The present paper aims at analyzing the listening activities of the Pupil's Book in Action Pack 5 to determine to what extent the first six units of in the Pupil's Book of action Pack 5 include listening activities. Moreover, it tries to investigate to what extent the first six units in the listening activities match the Listening Specific Outcomes in the Jordanian Guidelines. To answer the questions of the present study, frequencies and percentages are used. The findings of the analysis revealed that the listening lessons in the pupil's book of Action Pack 5 have a considerable variety in presenting the listening activities that activate and promote the internalization of learned material via active participation. Moreover, the study showed that there is a strong match between the listening specific outcomes and the listening activities' authenticity in Action Pack 5. In addition, the analysis pointed out the importance of flashcards, pictures and wall charts in presenting the listening activities. Furthermore, the study revealed the importance of conversation and pair work in developing students' oral communication.
\end{abstract}

Keywords: Content analysis, Listening activities, Listening specific outcomes, Action Pack

\section{Introduction}

English, as a universal language, becomes necessary in different fields of life. It is a must for most of the developed as well as developing countries to enter the era of globalization in an adequate manner. It is a main language in science, trade, education, and medicine so people, all over the world, depend on it heavily as a major mean of communication. People use it in 
their communication to transfer their ideas, opinions and point of views. One of the main purposes of teaching English by different ministries of education in the world, and especially in Jordan, is to teach the four language skills as one unit. The concentration in the Jordanian curricula is to help the learners to master the four language skills: reading, writing, speaking, and listening through presenting them in authentic contexts.

Jordanian Ministry of Education (2006, p.9) stated that:

"English is an international language and fundamental to learning and communicating in all cultures with the increasing amount of information and communication technology... Through learning English, the students will be able to develop confidence, competence and self-reliance to meet the demands of development and further education".

The above quotation shows the importance of English as a foreign language in the process of country's development in different fields of life as well as its importance in the process of education either on the school level or on the higher one.

In this paper, the content analysis would be to the listening activities that match the listening specific outcomes in the guidelines in the Jordanian pupil's book of Action Pack 5.As listening is an important skill that learners must learn and master. When learners are put in communicative activities, it is expected to take a part in the process of communication. Learners could not take an active part in this process unless they are able to comprehend what they are listening to. Learners must understand the speech that they are listening in order to take an active role in the process on interaction among themselves or even with their teacher. Consequently, teachers should do many efforts to develop and improve their learners' listening skill, because this will help their students to participate actively in the classroom's activities.

Teachers depend on textbooks and other supplementary material such as cassettes and CDs to teach listening, so the textbooks must be designed to help the teachers in doing so. There should be enough different listening activities to develop the learners' listening skill. The importance of listening as a skill stems from the fact that students who plan to continue their higher education are put to listening tests such as TOEFL for example. Students who are not good in this skill are expected to get poor marks in such tests. In some parts of the TOEFL exam, students are going also to listen to some short or long dialogues, and then they are asked to talk about a certain issue in the lecture or the dialogue that they listen to. This indicates the importance of the skills' integration in learning English as a foreign language.

Listening was defined by Bransford and McCarrell (1974) as an active process that requires from the learners the same ability of prediction, hypothesizing, revising, and checking. In doing so, it is expected that learners would be able to succeed in their tasks effectively; otherwise, they will fail in comprehending the material in an appropriate way.

\section{Description of Action Pack 5}

Action pack 5, which is published and organized by the Jordanian Ministry and Education, is a series of EFL textbooks. It is described by the Jordanian Ministry and Education as a communicative and modern English language course that helps in presenting English as a foreign language in its authentic contexts. It was published to be taught in the governmental 
Jordanian schools in its two educational stages; the lower and higher stages. It is expected that teaching this series in Jordan in an easy and interesting way will help the Jordanian students to master English in a proper way. Furthermore, it aims to encourage Jordanian learners to use the language actively outside and inside the classroom to become proficient users and communicators of English, which is considered a universal important language these days, by providing them with the opportunities to use the language in different interesting authentic contexts.

The Jordanian ministry of Education designed each course of Action Pack to have a Pupil's book, audiocassette, a Workbook, and a comprehensive Teacher's book.

The Ministry of Education divided Action Pack 5 into six modules; each module focuses on a particular theme that is relevant to the student's life. Each Module contains two units, which develop and present the theme of the unit in a different interesting way. Each unit is divided into eight lessons. Each lesson is designed to be presented between 40 to 45 minutes.

\section{Purpose of the Study}

The present study is based on the Specific Listening Outcomes under the listening Section in General Guidelines and General and Specific Outcomes for English Language in Jordan of 2006. It aims at investigating the extent to which the listening activities of the first six units in the pupil's book of Action Pack 5 are presented. Moreover, it aims at investigating the extent to which the listening activities of the first six units in the pupil's book of Action Pack 5 respond to the listening specific outcomes that develop the students' participation in the classroom exchanges and their use of pictures to understand new or unfamiliar words when listening.

\section{Sample of the Study}

The researcher selected six units out of twenty units randomly.

\section{Questions of the Study}

The current paper aims at answering the following questions:

1-To what extent do the first six units in the pupil's book of Action Pack 5 include listening activities?

2-To what extent do the listening activities of the first six units in the pupil's book of Action Pack 5 respond to the listening specific outcomes that develop the students' participation in the classroom exchanges and their use of pictures to understand new or unfamiliar words when listening?

\section{Statement of the Problem}

One of the problems that face learners in the different learning stages is the lack of understanding between the speaker and the listener due to the linguistic gab between them. When the listener could not understand what the speaker is saying, then there will be a problem in the process of interaction and communication between hem/her and his/her colleagues or teachers. The researcher have noticed this problem while teaching English in 
Jordan, UAE, and Saudi Arabia as students could not take an active part in the classroom's activities and discussions when they could not understand and comprehend what they are listening to.

In fact, the lack of the listening activities may result in the poor communication between the learners as it is so important for the textbooks to have a variety of listening activities as this may help them to improve their listening skill. Otherwise, learners could not be able to get good marks in the listening exams. Due to the importance of the listening as a receptive skill, the researcher tried to analyze one of Jordanian textbooks to see whether it contains appropriate listening activities that match the listening specific outcomes in the Jordanian guidelines that are set by the Ministry of Education in Jordan 2006.

\section{Review of Related Literature}

Salameh (2008) carried out a study to analyze the aspects of the communicative approach in the content of Action Pack 7 in Jordan. He conducted the study to find out to what extent the students' book of Action Pack 7 in Jordan includes the aspects of the communicative approach. The results of the study showed some of the positive points. For instance, the researcher found that the activities, which relate students to real life situations, was presented in an acceptable way. Moreover, the study revealed that the activities and the exercises that are presented in Action Pack 7 that show the importance of the four skills integration between the four language skills were insufficient as there should be more activities to develop the learners' communicative abilities.

Lee (2009) conducted a study to analyze a group of high-school EFL conversation textbooks to find out how the Korean textbooks teach culture in a listening and conversation activities. The conversation materials are chosen because the values and norms of socio-cultural are acquired better when they are designed to be taught in a process of interaction between students from one side and their teachers from the other side. The findings of the analysis showed that all of the textbooks neglect both the teaching of the culture-general aspect of culture learning and the small "c" target- culture learning which shows that the Korean textbooks are poor in presenting and teaching the Korean culture in the listening as well as the conversation activities.

In another study, Zawahreh (2012) presented a content analysis to the grammar activities in the six modules of the students' book of Action Pack Seven. He conducted that study to find out to what extent the grammar activities meet the criterion proposed by Celce-Murcia (1991). The results of the analysis pointed out that there is a good number of grammar activities compared to the total number of the activities in each Module. In addition, the analysis showed that all of the grammar activities meet the second criteria. Besides, the results showed that 55 out of the 60 grammar activities meet the criteria of "clarity and completeness". Finally, the content showed that fifty out of sixty grammar activities meet the fourth criteria of meaningful context as they are presented in meaningful context.

To find out the extent of the levels of the cognitive domain in the activities of the 10th grade textbooks according to Bloom's Taxonomy, Assaly and Igbaria (2013) analyzed two sections of "Mastering Reading" and "Mastering Listening". Six units were chosen to be the subject of 
the analysis for the two sections. The activities of the two section in the six unites were analyzed according to Bloom's Taxonomy: Lower-order thinking sills: analysis, synthesis, and evaluation. Percentages and frequencies were used to calculate the level of cognition for each unit. The analysis showed that 114 out 173 activities in Master Class emphasized the lower levels of cognition. Moreover, the analysis pointed out that $34.11 \%$ of the activities demand higher-order thinking from the students.

To investigate how well the 7 th and the 8 th grades textbooks matches the needs of the Pakistani learning program as well as the appropriateness of the activities in the Pakistani English textbooks "Step Ahead 2" and "Step Ahead 3"; Fatima, Shah, and Sultan (2015) conducted a content analysis to measure that appropriateness in the textbooks of the two grades. The results revealed that the textbooks have a lot of problems that need to be improved regarding the distribution of the four skills as well as the culture representation in the analyzed two books.

Mizbani and Chalak (2017) conducted a study to analyze the listening and the speaking activities of Iranian textbook "Prospect 3" through Bloom's revised Taxonomy. The aim behind that analysis was to find out to which level of lower or higher of the textbook's learning objectives related to Bloom's revised Taxonomy of the cognitive domain. The study pointed out that all of the speaking as well as the listening activities were classified as a low level of cognitive complexity. Moreover, the study revealed that these activities could not train the students in this grade to more advanced high levels of learning objectives.

\section{Methodology}

\subsection{Criteria of the Study}

The criteria of this study are the inclusion of the listening activities and the responding of the activities to the listening specific outcomes in the first six units in the pupil's book of Action Pack 5.

\subsection{Unit of Analysis}

The unit of analysis is the listening activity in the first six units of Action Pack 5.

\subsection{Definition of Terms}

1- Inclusion Criterion: It is the inclusion of listening activities that develop the learning of participation in classroom exchanges and using pictures to understand new or unfamiliar words when listening in the first six units of Action Pack 5.

2- Listening Activities: They are the listening activities that are presented by the teacher in the classroom, with a recorder in the first six units of Action Pack 5.

3- Listening Specific Outcomes: They are the ability of developing the learning of participating in class exchanges and using pictures to understand new or unfamiliar words when listening to the tasks that are presented in the pupil's book of Action Pack 5.

4- Action Pack 5 Listening Specific Outcomes: They are the Listening Specific Outcomes in the General Guidelines and General and Specific Outcomes for English Language in 
Jordan 2006 (p.31). These outcomes are arranged in three groups. In following these outcomes, by teachers in their teaching, students are expected to:

Group One

L5.1.1 recognize the different sounds of some consonants alphabet (e.g., city, cat, good, general).

Group Two

L5.2.1 follow simple oral instructions

L5.2.2 participate in simple classroom exchanges

L5.2.3 respond to questions before, during, and after listening

L5.2.4 begin to make inferences when listening

L5.2.5 show appropriate to rhymes and songs

Group Three

L5.3.1 use pictures to understand new or unfamiliar words when listening

L5.3.2 use clues to understand new words when listening

L5.3.3 take notes when listening to remember the main idea

\subsection{Categories of the Study}

The categories of this study are the listening types of the listening activities in the first six units of Action Pack 5; they are the following three groups:

Group One

L5.1.1. recognize the different sounds of some consonants alphabet (e.g., city, cat, good, general).

\section{Group Two}

\section{L5.2.1 follow simple oral instructions}

\section{L5.2.2 participate in simple classroom exchanges}

L5.2.3 respond to questions before, during, and after listening

L5.2.4 begin to make inferences when listening

L5.2.5 show appropriate to rhymes and songs

\section{Group Three}

\section{L5.3.1 use pictures to understand new or unfamiliar words when listening}

L5.3.2 use clues to understand new words when listening

L5.3.3 take notes when listening to remember the main idea

They are classified according to the following two listening specific outcomes:

1 - Participating in classroom exchanges.

2- Using pictures to understand new or unfamiliar words when listening.

\subsection{Limitations of the Study}

The content analysis is limited to the first six units in the pupil's book of Action Pack 5. Moreover, the researcher chose only the second specific outcome in the second group and the first specific out come in the third group.

Group Two

\section{L5.2.2 participate in simple classroom exchanges}

Group Three

L5.3.1 use pictures to understand new or unfamiliar words when listening 


\subsection{Validity of the Instrument}

The textbook under analysis consists of six Modules. The module in each unit concentrates on a particular theme. Each Module contains two units. Each unit in the Module consists of different activities to measure the learners' linguistic abilities in the four language skills. In the unit, learners have to deal with different activities such as pre-reading, writing, vocabulary, grammar, and listening ones.

To ensure the content validity of the research instrument, a jury of TEFL professors at Yarmouk University, three English language at Jerash Educational Directorate who have been teaching English for the basic stage for twelve years, were asked politely to participate in determining the validity of the criteria and to give their feedback about the validity of the criteria. The researcher took their comments, suggestions, and advices taken into consideration. The criteria were modified according to their comments.

\subsection{Reliability of the Instrument}

The content analysis was carried out by three of the qualified English language teachers who have been teaching English for more than ten years. The researcher as well as another two colleagues analyzed the listening activities that are presented in the first six units in the Pupil's book of Action Pack 5.They repeated the analysis to ensure the reliability of it after two weeks from the first analysis using the same units of analysis. The consistency between the two analyses was found (0.96). This percentage shows the high consistency between the two analyses as well as a high reliability of the two analyses that were done by the researcher as well as the other two colleagues.

This study is designed to be a qualitative as well as a quantitative one. To analyze the content under studying, the researcher employed the quantitative methodology. Frequencies and percentages of the activities represent the criteria of analysis. The researcher used the qualitative methodology to get a better general understanding of the content of the listening activities that are presented in the first six units in the pupil's book of Action Pack 5.

\section{Findings and Discussion}

Table 1 presents the frequencies and percentages of the listening activities that are included in the first six units in the pupil's book of Action Pack 5 compared to the total number of listening activities. 
Table 1. Frequencies and Percentages of Listening Activities in the first Six Units in the Pupil's Book of Action Pack 5

\begin{tabular}{|c|l|c|}
\hline Unit Number/Title & $\begin{array}{l}\text { Frequencies and } \\
\text { Percentages }\end{array}$ & $\begin{array}{l}\text { Total and Percentage of Listening } \\
\text { Activities Per Unit }\end{array}$ \\
\hline \multirow{2}{*}{ 1/Have We Got Any Paper? } & Frequency per Unit & 3 \\
\cline { 2 - 3 } & Percentage per Unit & 18.75 \\
\hline \multirow{2}{*}{ 2/ How Do You Make It? } & Frequency per Unit & 3 \\
\cline { 2 - 3 } & Percentage per Unit & 18.75 \\
\hline \multirow{2}{*}{ 3/That Smells Delicious! } & Frequency per Unit & 2 \\
\cline { 2 - 3 } & Percentage per Unit & 12.5 \\
\hline \multirow{2}{*}{ 4/Revision: The School Magazine } & Frequency per Unit & 2 \\
\cline { 2 - 3 } & Percentage per Unit & 12.5 \\
\hline 5/How Often Do You Visit Them? & Frequency per Unit & 3 \\
\cline { 2 - 3 } & Percentage per Unit & 18.75 \\
\hline \multirow{2}{*}{ 6/A Trip to Town } & Frequency per Unit & 3 \\
\cline { 2 - 3 } & Percentage per Unit & 18.75 \\
\hline \multirow{2}{*}{ Total } & Frequency & 100 \\
\cline { 2 - 3 } & Percentage & \\
\hline
\end{tabular}

The table shows that there are sixteen listening activities. These listening activities have been distributed in the six units. The table shows that Unit One, Two, Five, and Six have the same number of listening activities. There are three activities in each Unit. On the other hand, the lowest percentage of the listening activities appears in Unit Three and Unit Four. In Unit One, three listening activities are introduced. They are the following: Listen and read, Listen and match, and Listen and choose. In Unit Two, there are also 3 listening activities. They are the following: Listen and read, Listen and order, and Listen and match. On the other hand, only 2 listening activities are introduced in Unit Three. They are: Listen and read and sing. Unit Four has also 2 listening activities. They are the following: Listen and read, and listen and choose, and sing.

Unit Five has 3 listening activities. They are: Listen and read, Listen and read, Listen and choose. As for Unit six, the table shows that it has three listening activities. They are the following: Listen and read, Listen and find, and listen and follow the directions as in exercise 4 on page 25.In this exercise, pupils are asked to read the names of the places. Next, pupils are asked to listen to the cassette and follow the given directions. The exercise talks about some places such as the mosque, the library, the computer shop, and the pharmacy. It is a conversation between two boys. One of them is asking about the post office. The other boy is telling him about the right directions to reach the post office. Unit One is entitled "Have We Got Any Paper?" It is a story that comes as an opening for every unit. The teacher may pre-teach any new vocabulary using flashcards or wall charts as prompts. In this lesson, pupils are asked to describe what they can see in the picture. They are asked to listen and read the conversation between Fatima and her brother Saleem. Lesson 1 in each unit consists of a short story, presented around story frames. 
Unit Two is entitled "How Do You Make It?" The first listening lesson is a conversation between a mother and her daughter. The mother is going to make her daughter's favorite meal "Lamb and rice". She is telling her daughter about the way of making this meal. The teacher may ask some questions such as: What can you see in the picture? Or he may ask pupils to guess what they think is happening in the story before they read and listen.

The table shows that Unit Three has two listening activities although it is an important and interesting unit. The importance of this unit comes from its title. It is entitled "That Smells Delicious!" Pupils feel happy when they are asked to listen and talk about their favorite meals. The lesson talks about the meal of rice and lamb that was prepared by the mother for their guests. The researcher believes that this unit should contain many listening activities because students enjoy listening and talking about their interest and especially about their favorite meals and about the different kinds of food they are fond of.

Unit Four has also two listening lessons. The first lesson is entitled "Listen and read". It is about Fatima's letter to her friends talking about her favorite meal. The second lesson is "Listen and choose" It is about Ibrahim's room. Here the pupils are going to listen and choose the pictures that match the text.

Table 2 presents the frequencies and percentages of listening activities that are classified according to the two listening specific outcomes that are found in the first six units in the pupil's book of Action Pack 5 compared to the total number of listening activities.

Table 2. Frequencies and Percentages of Listening Activities per each Unit in the Pupil's Book of Action Pack 5 According to the Two Listening Specific Outcomes

\begin{tabular}{|c|c|c|c|c|}
\hline \multirow[t]{2}{*}{$\begin{array}{c}\text { Unit/ } \\
\text { Number/Tile }\end{array}$} & \multirow[t]{2}{*}{$\begin{array}{l}\text { Frequencies and } \\
\text { Percentages }\end{array}$} & $\begin{array}{c}\text { Listening Outcome } \\
1 \text { (L5.2.2) } \\
\end{array}$ & $\begin{array}{c}\text { Listening Outcome } 2 \\
\text { (L5.3.1) }\end{array}$ & \multirow{2}{*}{$\begin{array}{c}\text { Total and } \\
\text { Percentage } \\
\text { of Listening } \\
\text { Activities Per Unit }\end{array}$} \\
\hline & & $\begin{array}{l}\text { Participating in } \\
\text { Simple Class } \\
\text { Exchanges }\end{array}$ & $\begin{array}{l}\text { Using Pictures to understand } \\
\text { New or Unfamiliar Words } \\
\text { When Listening }\end{array}$ & \\
\hline \multirow{2}{*}{$\begin{array}{l}\text { 1/Have We Got } \\
\text { Any Paper? }\end{array}$} & Frequency Per Unit & 1 & 2 & 3 \\
\hline & Percentage Per Unit & 6.25 & 12.25 & 18.5 \\
\hline \multirow{2}{*}{$\begin{array}{l}\text { 2/ How Do } \\
\text { You Make It? }\end{array}$} & Frequency Per Unit & 1 & 2 & 3 \\
\hline & Percentage Per Unit & 6.25 & 12.25 & 18.50 \\
\hline \multirow{2}{*}{$\begin{array}{l}\text { 3/That Smells } \\
\text { Delicious! }\end{array}$} & Frequency Per Unit & 1 & 1 & 2 \\
\hline & Percentage Per Unit & 6.25 & 6.25 & 12.50 \\
\hline \multirow{2}{*}{$\begin{array}{l}\text { 4/Revision: } \\
\text { The School } \\
\text { Magazine }\end{array}$} & Frequency Per Unit & 1 & 1 & 2 \\
\hline & Percentage Per Unit & 6.25 & 6.25 & 12.50 \\
\hline \multirow{2}{*}{$\begin{array}{l}\text { 5/How Often } \\
\text { Do You Visit } \\
\text { Them? }\end{array}$} & Frequency Per Unit & 2 & 1 & 3 \\
\hline & Percentage Per Unit & 12.25 & 6.25 & 18.75 \\
\hline \multirow{2}{*}{$\begin{array}{l}\text { 6/A Trip to } \\
\text { Town }\end{array}$} & Frequency Per Unit & 3 & - & 3 \\
\hline & Percentage Per Unit & 18.75 & - & 18.75 \\
\hline \multirow[t]{2}{*}{ Total } & Frequency & 9 & 7 & 16 \\
\hline & Percentage & 56.25 & 34.75 & 100 \\
\hline
\end{tabular}




\section{MInstitute ${ }_{\text {Mnin }}^{\text {Macrothin }}$}

Quantitatively speaking, Table 2 shows that 9 activities out of 16 in the first six units in the pupil's book of Action Pack 5 require participating in simple class exchanges with a total percentage of $56.25 \%$. Such focus on this outcome highlights the significance of pupil's participation in the classroom. It is said that the students' participation in the classroom's activities is an obvious indicator for the students' involvement and understanding to the presented activities (Kurtz, 2001; Sang, 2006; Miao, 2007; Sun, 2008).

These activities could be found in lesson 1 on page 4 . This lesson is a conversation between Fatima and Saleem. In this lesson pupils have to listen carefully to the cassette and then they have to answer the questions that are going to be written by the teacher. Then the pupils are asked to act the dialogue. Another example is lesson 2 on page 13.In this lesson, pupils are asked to listen to a song on the cassette. Then they are asked to read the words of the song as they listen. After that, pupils are going to participate in singing the song in chorus as an indicator to the importance of pupils' participation in the classroom's activities. By doing so, pupils are expected to use and practice the language in authentic contexts.

Another example can be found on page 16.The title of the lesson is "Jordan" It is a letter that was written by Fatima to her friends telling them to send their stories about their homes and favorite meals. Pupils are asked to listen to the cassette. Next, they are going to answer the questions that the teacher is going to write on the board such as:

What is Fatima's favorite meal?

What is the magazine called?

What does she want you to do?

Lesson 2 on page 20 requires full participation in the class. This lesson is entitled "Listen and choose "It is a dialogue between Sameer and Hisham. They are talking about their activities. The teacher asks pupils to look at the table, after that, he asks pupils to make the questions. The teacher gives the first one as an example. The teacher writes on the board:

How often do you ..........? Pupils are asked to form questions using this model:

A: How often do you brush your teeth?

B: Three times a day.

Then, pupils are asked to listen to the dialogue and they have to say which boy is speaking Sameer or Hisham.

Regarding the second specific outcome, the table shows that only 7 activities out of 16 activities require using pictures to understand new or unfamiliar words when listening. These activities can be found in lesson 2 on page 5 and lesson 4 on page 6 (Unit 1),Lesson 2 on page 9 (Unit 2),Lesson 2 on page 13 (Unit 3), Lesson 2 on page 17 (Unit 4). In lesson 2 on page 5 (Unit 1), pupils are asked to listen and choose the picture that matches the description. In this lesson, pupils will hear somebody describing one of the pictures. Pupils must listen and choose the picture that matches the description. In lesson 4 on page 6 (Unit 1), there are three pictures. In this lesson, pupils will hear three conversations with two people talking. Pupils 
have to match the conversations with the pictures. This lesson requires the active participation from the pupils because they have to say if they agree or not on what the two girls are talking about.

Using pictures in the learning process is necessary and important as they facilitate understanding the lesson being presented to the student (Bishop, 1977; Ernestova, 1981; Skrzypenska, 1992). Moreover, it is expected that engaging student in some useful picture activities will develop their linguistic ability as well as their cognitive engagement (Hsiao, 2010; Ellia, van den Heuvel-Panhuize, \& Georgiou, 2010).

Another example that shows the importance of using pictures to understand new or unfamiliar words when listening is lesson 1 (Unit 3). The Unit is entitled "That Smells Delicious!" The lesson is full of pictures that facilitate pupils' understanding to the listening lesson. The pupils can see pictures of lamb, rice, pastry, and salad. Lesson 2 on page 17 (Unit 4) consists of a lot of pictures that help in understanding the lesson. The pupils can see a cupboard, a magazine, a desk, a chair and some stories. The importance of these pictures comes from the fact that can be used to present or reinforce new language.

In Unit 5 that is entitled "How Often Do You Visit Them?" There is a song on page 21. In this lesson, three pictures are used to facilitate the pupil's understanding to the theme of the song. The pupils can see two boys. One of them is playing football while the other is reading. There is a girl who is playing the piano. Using these pictures will help the pupils to understand the lesson in a good way.

In this field, Ernestova (1981, pp.5-9) suggests using the pictures in the learning process at all levels as they play a positive role in facilitating the learners' performance. She indicates that teachers can pictures can be used to achieve many educational aims such as (1) introducing new lexical items at the beginning of each lesson, (2) illustrating a new grammar structure as pictures facilitate presenting the new grammar for the learners, and (3) eliminating some pronunciation difficulties. She also believes that pictures play a very important role in motivating the students to participate in the classroom activities actively to reflect their engagement in the learning process.

\section{Conclusion}

The findings of the analysis revealed that there is a considerable variety in presenting the listening activities in the six units of Action Pack 5 which shows the significance of the listening skill particularly at the primary stage. The variety of such these listening activities helps in developing the pupils' language competence. Moreover, the analysis showed that the listening activities inaction Pack 5 are integrated with other language skills especially speaking and reading skills. The integration of the four language skills in necessary as it facilitated the language learning especially for the foreign language learners. Furthermore, the analysis pointed out the importance of flashcards, pictures and wall charts in presenting the listening activities. The results of Bishop (1977), Ernestova (1981), Skrzypenska (1992), Hsiao (2010), and Ellia, van den Heuvel-Panhuize (2010) go in complete harmony with what the present study confirms on the necessity of using pictures to develop the learners' linguistic competence. In addition, the findings revealed that the two specific listening outcomes are 
represented in the first six units of Action Pack 5 in an excellent way.

\section{References}

Assaly, I., \& Igbaria, A. (2013). A Content analysis of the Levels of the Cognitive Domain in the activities of the $10^{\text {th }}$-Grade Textbooks, "Master Class", According to Bloom's Taxonomy. Educational Journal, 3(2), 24-38.

Bishop, A. (1977). Is a picture worth a thousand words? Mathematics Teaching, 8(1), 32-35.

Bransford, J., \& McCarrell, N. (1974). A Sketch of a Cognitive Approach to Comprehension: Some Thoughts abut Understanding What it Means to Comprehend. Retrieved January 20, 2018, from https://www.researchgate.net/publication/232481803_A_sketch_of_a_cognitive_

Elia, I., van den Heuvel-Panhuizen, M., \& Georgiou, A. (2010). The Role of Pictures in Picture Books on Children's Cognitive Engagement with Mathematics Images. European Early Childhood Education Research Journal, 18(3), 125-147.

Ernestova, M. (1981). How to Use Ready-Made Pictures. Teaching English Forum, XIX(4), 278-283.

Hsiao, C. Y. (2010). Enhancing Children's Artistic and Creative Thinking and Drawing Performance through Appreciating Picture Books. International Journal of Art \& Design Education, 29(2), 143-152.

Kurtz, P. (2001). The Effects of classroom Interaction. A Comparison of Distance and Non-Distance Learning English Classes. Retrieved January 15, 2018, from http://proquest.umi.com.pqdweb?did=1306834591

Lee, K. (2009). Treating culture: What 11 high school EFL conversation textbooks in South Korea do. English Teaching: Practice and Critique. Retrieved January 10, 2018, from http://education.waikato.ac.nz/research

Miao, P. (2005). Scaffolding and Participation in Classroom Interaction. Retrieved January 18, 2018, from http://proquest.umi.com/pqdweb?did

Ministry of Education. (2006). General guidelines and general and specific outcomes for the English language curriculum. Amman: Al-Watanya Press.

Mizbani, M., \& Chalak, A. (2017). Analyzing Listening and Speaking Activities of Iranian EFL Textbook "Prospect 3" Through Bloom's Revised Taxonomy. Advance in Language and Literary Studies, 8(3), 38-49.

Salameh, Z. (2008). An analysis of the aspects related to the communicative approach in the content of the Action Pack for the seventh grade. Unpublished M. Thesis, Yarmouk University, Irbid.

Sang, L. (2006). The Influence of Student-Teacher Interactions on Students' Engagement. Retrieved January 16, 2018 from http://proquest.umi.com/pqdweb?did=1306834591

Skrzypenska, J. (1992). Some Ways to Use Pictures in Language Teaching. FORUM, III, 2. 


\section{Macrothink Institute ${ }^{\text {tm }}$}

Sun, Y. (2008). Motivation to Speak: Perception of Attitude of Non - English Major Students. Retrieved January 10, 2018, from http://proquest.umi.com.ezproxy.yu.edu.jo.:2045

Sutan, H. (2015). Textbook Analysis and Evaluation of $7^{\text {th }}$ and $8^{\text {th }}$ Grade in Pakistani Context. International Journal of English Teaching, 3(4), 79-97.

Zawahreh, F. (2012). A Content Analysis of Grammar Activities in Pupil's Book of Action Pack Seven as a Textbook for Teaching English as a Foreign Language in Jordan. Language in India, 12(4), 161-158.

\section{Copyright Disclaimer}

Copyright reserved by the authors.

This article is an open-access article distributed under the terms and conditions of the Creative Commons Attribution license (http://creativecommons.org/licenses/by/3.0/). 